\title{
Association of genetic variants with chronic kidney disease in Japanese individuals with type 2 diabetes mellitus
}

\author{
TETSURO YOSHIDA ${ }^{1}$, KIMIHIKO KATO $^{2}$, KIYOSHI YOKOI $^{2}$, SACHIRO WATANABE $^{3}$, \\ NORIFUMI METOKI ${ }^{4}$, HIDEMI YOSHIDA $^{5}$, KEI SATOH ${ }^{5}$, YUKITOSHI AOYAGI $^{6}$, \\ YUTAKA NISHIGAKI $^{6}$, TAKAO SUZUKI ${ }^{7}$, YOSHINORI NOZAWA ${ }^{8}$ and YOSHIJI YAMADA ${ }^{9}$
}

\begin{abstract}
${ }^{1}$ Department of Cardiovascular Medicine, Inabe General Hospital, Inabe; ${ }^{2}$ Department of Cardiovascular Medicine, Gifu Prefectural Tajimi Hospital, Tajimi; ${ }^{3}$ Department of Cardiology, Gifu Prefectural General Medical Center, Gifu;

${ }^{4}$ Department of Internal Medicine, Hirosaki Stroke Center; ${ }^{5}$ Department of Vascular Biology, Institute of Brain Science, Hirosaki University Graduate School of Medicine, Hirosaki; ${ }^{6}$ Department of Genomics for Longevity and Health and ${ }^{7}$ Research Team for Promoting Independence of the Elderly, Tokyo Metropolitan Institute of Gerontology,

Tokyo; ${ }^{8}$ Gifu International Institute of Biotechnology, Kakamigahara; ${ }^{9}$ Department of Human

Functional Genomics, Life Science Research Center, Mie University, Tsu, Japan
\end{abstract}

Received November 20, 2008; Accepted January 13, 2009

DOI: 10.3892/ijmm_00000161

\begin{abstract}
Although diabetes mellitus has been recognized as a risk factor for chronic kidney disease (CKD), genetic factors for predisposition to CKD in individuals with diabetes mellitus remain elucidated. The purpose of the present study was to identify genetic variants that confer susceptibility to CKD among individuals with type 2 diabetes mellitus. The study population comprised 1742 Japanese individuals, including 636 subjects with CKD [estimated glomerular filtration rate (eGFR) $\left.<60 \mathrm{ml} / \mathrm{min} / 1.73 \mathrm{~m}^{2}\right]$ and 1106 controls $\left(\mathrm{eGFR} \geq 60 \mathrm{ml} / \mathrm{min} / 1.73 \mathrm{~m}^{2}\right)$. The genotypes for 24 polymorphisms of 22 candidate genes were determined. An initial screen of allele frequencies by the Chi-square test revealed that four polymorphisms were significantly (false discovery rate $<0.05$ ) associated with the prevalence of CKD in individuals with type 2 diabetes mellitus. Subsequent multivariable logistic regression analysis with adjustment for covariates as well as a stepwise forward selection procedure revealed that the $8733 \mathrm{~T} \rightarrow \mathrm{C}$ polymorphism of ALOX5AP (rs3803278), the $\mathrm{C} \rightarrow \mathrm{T}$ (Ser532Leu) polymorphism of IRAK1 (rs1059703), and the 2445G $\rightarrow \mathrm{A}$ (Ala54Thr) polymorphism of FABP2 (rs 1799883) were significantly $(\mathrm{P}<0.05)$ associated with the prevalence of CKD. Our results suggest that $A L O X 5 A P, I R A K 1$, and FABP2 are susceptibility loci for CKD among Japanese individuals with type 2 diabetes mellitus.
\end{abstract}

Correspondence to: Dr Yoshiji Yamada, Department of Human Functional Genomics, Life Science Research Center, Mie University, 1577 Kurima-machiya, Tsu, Mie 514-8507, Japan E-mail: yamada@gene.mie-u.ac.jp

Key words: genetics, polymorphism, chronic kidney disease, type 2 diabetes mellitus, end stage renal disease

\section{Introduction}

Chronic kidney disease (CKD) is a major risk factor for end stage renal disease (ESRD) and also an independent risk factor for all-cause death or cardiovascular disease in the general population (1-3), as well as in high-risk populations $(4,5)$. Identification of genetic markers for CKD risk is thus important both for risk prediction and for intervention to avert future ESRD and cardiovascular events.

Diabetes mellitus has been recognized as an important risk factor for developing proteinuria $(6,7)$ and progression to renal dysfunction $(8,9)$ as well as a major source of morbidity and mortality in patients with established CKD (10). In addition, diabetic nephropathy is one of the most serious chronic complications among patients with diabetes mellitus (11), and is associated with increased cardiovascular mortality (12). Although diabetes mellitus is an important risk factor for CKD, genetic factors for predisposition to CKD in individuals with type 2 diabetes mellitus remain largely unknown. Furthermore, given the ethnic differences in lifestyle and environmental factors as well as in renal function and genetic background, it is important to examine genetic variants related to CKD in individuals with type 2 diabetes mellitus in each ethnic group.

We have now performed an association study for 24 polymorphisms of 22 candidate genes and CKD in 1742 Japanese individuals with type 2 diabetes mellitus. The purpose of the present study was to identify genetic variants that confer susceptibility to CKD among individuals with type 2 diabetes mellitus and thereby to provide a basis for the personalized prevention of this condition.

\section{Materials and methods}

Study population. The study population comprised 1742 unrelated Japanese individuals (1158 men, 584 women) who either visited outpatient clinics of or were admitted to one of 
Table I. The 24 polymorphisms of 22 genes examined in the study.

\begin{tabular}{|c|c|c|c|c|}
\hline Locus & Gene & Symbol & Polymorphism & $\mathrm{dbSNP}^{\mathrm{a}}$ \\
\hline $1 q 23-q 25$ & Selectin E & SELE & $561 \mathrm{~A} \rightarrow \mathrm{C}(\operatorname{Ser} 128 \mathrm{Arg})$ & rs5361 \\
\hline $1 \mathrm{q} 31-\mathrm{q} 32$ & Interleukin 10 & IL10 & $-819 \mathrm{~T} \rightarrow \mathrm{C}$ & rs1800871 \\
\hline $1 \mathrm{q} 31-\mathrm{q} 32$ & Interleukin 10 & ILIO & $-592 \mathrm{~A} \rightarrow \mathrm{C}$ & rs1800872 \\
\hline $2 q 31$ & Collagen, type III, alpha-1 & COL3A1 & $3730 \mathrm{~A} \rightarrow \mathrm{G}(\mathrm{Ile} 1205 \mathrm{Val})$ & rs2271683 \\
\hline $3 \mathrm{p} 21.31$ & SREBF cleavage-activating protein & $S C A P$ & 2386A $\rightarrow \mathrm{G}(\mathrm{Ile} 796 \mathrm{Val})$ & rs12487736 \\
\hline $3 q 27$ & Adipocyte, $\mathrm{C} 1 \mathrm{Q}$, and collagen domain containing & $A D I P O Q$ & $62 \mathrm{G} \rightarrow \mathrm{T}$ & rs 1501299 \\
\hline $4 q 28-q 31$ & Fatty acid-binding protein 2 & $F A B P 2$ & 2445G $\rightarrow$ A (Ala54Thr $)$ & rs 1799883 \\
\hline $5 q 34$ & $\begin{array}{l}\text { Potassium channel, calcium-activated, large conductance, } \\
\text { subfamily M, B member } 1\end{array}$ & $K C N M B 1$ & $\mathrm{G} \rightarrow \mathrm{A}$ (Glu65Lys) & rs11739136 \\
\hline $6 \mathrm{p} 21.3$ & Tumor necrosis factor & $T N F$ & $-850 \mathrm{C} \rightarrow \mathrm{T}$ & rs1799724 \\
\hline $6 \mathrm{p} 12$ & Vascular endothelial growth factor & $V E G F$ & $936 \mathrm{C} \rightarrow \mathrm{T}$ & rs3025039 \\
\hline $7 q 21.3-q 22$ & Plasminogen activator inhibitor 1 & PAII & $A \rightarrow G$ (Tyr243Cys) & rs 13306846 \\
\hline 7q22.1 & Cytochrome P450, subfamily IIIA, polypeptide 4 & СYР $3 A 4$ & 13989A $\rightarrow$ G (Ile118Val) & (NC_000007.12) \\
\hline $8 \mathrm{p} 12$ & Plasminogen activator, tissue & PLAT & $-7351 \mathrm{C} \rightarrow \mathrm{T}$ & rs2020918 \\
\hline $9 q 32-q 33.3$ & Prostaglandin-endoperoxide synthase 1 & PTGS1 & $\mathrm{C} \rightarrow \mathrm{T}$ & rs883484 \\
\hline $13 q 12$ & Arachidonate 5-lipoxygenase-activating protein & $A L O X 5 A P$ & $8733 \mathrm{~T} \rightarrow \mathrm{C}$ & rs3803278 \\
\hline $13 q 34$ & Factor VII & F7 & $11496 \mathrm{G} \rightarrow \mathrm{A}(\mathrm{Arg} 353 \mathrm{Gln})$ & rs6046 \\
\hline $16 \mathrm{p} 11.2$ & Vitamin K epoxide reductase complex, subunit 1 & VKORC1 & $2255 \mathrm{~T} \rightarrow \mathrm{C}$ & rs2359612 \\
\hline $17 q 23$ & Platelet-endothelial cell adhesion molecule 1 & PECAMI & $1454 \mathrm{C} \rightarrow \mathrm{G}(\mathrm{Leu} 125 \mathrm{Val})$ & rs668 \\
\hline $19 \mathrm{q} 13.2$ & Apolipoprotein E & APOE & $-219 \mathrm{G} \rightarrow \mathrm{T}$ & rs405509 \\
\hline $19 \mathrm{q} 13.2$ & Apolipoprotein E & $A P O E$ & 3932T $\rightarrow \mathrm{C}(\mathrm{Cys} 112 \mathrm{Arg})$ & rs429358 \\
\hline $22 q 11.2$ & Catechol-O-methyltransferase & COMT & $\mathrm{G} \rightarrow \mathrm{A}($ Val158Met $)$ & rs4680 \\
\hline $\mathrm{Xq} 28$ & Interleukin 1 receptor-associated kinase 1 & IRAKI & $\mathrm{C} \rightarrow \mathrm{T}$ & rs7061789 \\
\hline $\mathrm{Xq} 28$ & Interleukin 1 receptor-associated kinase 1 & IRAKI & $\mathrm{C} \rightarrow \mathrm{T}(\mathrm{Ser} 532 \mathrm{Leu})$ & rs 1059703 \\
\hline Xq28 & Interleukin 1 receptor-associated kinase 1 & IRAKI & $\mathrm{A} \rightarrow \mathrm{C}$ & rs3027898 \\
\hline
\end{tabular}

${ }^{a}$ In instances in which rs numbers in dbSNP were not detected, NCBI GenBank accession numbers are shown in parentheses.

the participating hospitals (Gifu Prefectural General Medical Center and Gifu Prefectural Tajimi Hospital in Gifu Prefecture, Japan; and Hirosaki University Hospital, Reimeiko Rehabilitation Hospital, and Hirosaki Stroke Center in Aomori Prefecture, Japan) between October 2002 and March 2008 because of various symptoms or for an annual health checkup, or who were recruited to a population-based prospective cohort study of aging and age-related diseases in Gunma Prefecture and Tokyo, Japan. Glomerular filtration rate was estimated with the use of the simplified prediction equation derived from the modified version of that described in the Modification of Diet in Renal Disease (MDRD) Study as proposed by the Japanese Society of Nephrology (13): eGFR ( $\mathrm{ml} \mathrm{min}^{-1} 1.73 \mathrm{~m}^{-2}$ ) $=194 \times$ [age $($ years $)]^{-0.287} \times$ [serum creatinine $\left.(\mathrm{mg} / \mathrm{dl})\right]^{-1.094} \mathrm{x}$ [0.739 if female]. The National Kidney Foundation-Kidney Disease Outcomes Quality Initiative guidelines recommend a diagnosis of CKD if eGFR is $<60 \mathrm{ml} \mathrm{min} \mathrm{m}^{-1} 1.73 \mathrm{~m}^{-2}$ (14). Nonlinear relations between GFR and the risk of adverse events, such as death, cardiovascular events, and hospitalization, have been demonstrated, with an increased risk being associated with an eGFR of $<60 \mathrm{ml} \mathrm{m^{-1 }} 1.73 \mathrm{~m}^{-2}$ (1). We thus adopted the criterion of an eGFR of $<60 \mathrm{ml} \mathrm{min}^{-1} 1.73 \mathrm{~m}^{-2}$ for diagnosis of CKD in the present study. On the basis of this criterion, 636 subjects (421 men, 215 women) were diagnosed with CKD. The control subjects comprised 1106 controls (737 men, 369 women) whose eGFR was $\geq 60 \mathrm{ml} \mathrm{min}^{-1} 1.73 \mathrm{~m}^{-2}$. The diagnosis of diabetes mellitus was defined as fasting blood glucose of $\geq 6.93 \mathrm{mmol} / \mathrm{l}$ or hemoglobin $\mathrm{A}_{1 \mathrm{c}}$ of $\geq 6.5 \%$, or both, or taking antidiabetes medication.

Type 2 diabetes mellitus was defined according to the criteria accepted by the World Health Organization and described previously $(15,16)$. Individuals with type 1 diabetes mellitus, with maturity-onset diabetes of the young, with other metabolic or endocrinologic diseases, or with severe liver dysfunction were excluded from the study. Individuals taking drugs that cause secondary diabetes mellitus were also excluded. Subjects with CKD and controls either had or did not have other conventional risk factors for CKD, including hypertension (systolic blood pressure of $\geq 140 \mathrm{mmHg}$ or diastolic blood pressure of $\geq 90 \mathrm{mmHg}$, or both, or taking antihypertensive medication), or hypercholesterolemia (serum total cholesterol of $\geq 5.72 \mathrm{mmol} / \mathrm{l}$ or taking lipid-lowering medication). The study protocol complied with the Declaration of Helsinki and was approved by the Committees on the Ethics of Human Research of Mie University Graduate School of Medicine, Hirosaki University Graduate School of Medicine, Gifu International Institute of Biotechnology, Tokyo Metropolitan Institute of Gerontology, and participating 
hospitals. Written informed consent was obtained from each participant.

Selection of polymorphisms. Our aim was to identify genes associated with CKD in the Japanese population with type 2 diabetes mellitus in a case-control association study by examining the relations of one to three polymorphisms of each candidate gene to this condition. With the use of public databases, including PubMed (NCBI) and Online Mendelian Inheritance in Man (OMIM), we selected 22 candidate genes that have been characterized and suggested to be associated with CKD. On the basis of published studies or by searching PubMed and single nucleotide polymorphism (SNP) databases [dbSNP (NCBI) and Japanese SNP database (JSNP)], we further selected 24 polymorphisms of these genes, most located in the promoter region or exons, that might be expected to result in changes in the function or expression of the encoded protein (Table I). Wild-type and variant alleles of the polymorphisms were determined from the original sources.

Genotyping of polymorphisms. Venous blood $(7 \mathrm{ml})$ was collected into tubes containing $50 \mathrm{mmol} / \mathrm{l}$ ethylenediaminetetraacetic acid (disodium salt), and genomic DNA was isolated with a kit (Genomix; Talent, Trieste, Italy). Genotypes of the 24 polymorphisms were determined at G\&G Science (Fukushima, Japan) by a method that combines the polymerase chain reaction (PCR) and sequence-specific oligonucleotide probes with suspension array technology (Luminex, Austin, TX). Primers, probes, and other PCR conditions for genotyping polymorphisms found to be related [false discovery rate $(\mathrm{FDR})<0.05]$ to $\mathrm{CKD}$ by the Chi-square test are shown in Table II. Detailed genotyping methodology was described previously (17).

Statistical analysis. Quantitative data were compared between subjects with CKD and controls by the unpaired Student's t-test. Categorical data were compared by the Chi-square test. Allele frequencies were estimated by the gene counting method, and the Chi-square test was used to identify departures from Hardy-Weinberg equilibrium. In the initial screen, allele frequencies $(2 \times 2)$ of each polymorphism were compared between subjects with CKD and controls by the Chi-square test. Given the multiple comparisons of genotypes with CKD, the FDR was calculated from the distribution of P-values for allele frequency of the 24 polymorphisms (18).

Polymorphisms with an FDR of $<0.05$ were further examined by multivariable logistic regression analysis with adjustment for covariates. Multivariable logistic regression analysis was thus performed with CKD as a dependent variable and independent variables including age, gender $(0=$ woman, $1=$ man $)$, smoking status $(0=$ nonsmoker, $1=$ smoker $)$, history of hypertension ( $0=$ no history, $1=$ positive history), and genotype of each polymorphism; P-values, odds ratios, and 95\% confidence intervals were calculated. Each genotype was assessed according to dominant $(0=$ wild-type homozygote, 1 = heterozygote $=$ variant homozygote $)$, recessive $(0=$ wild-type homozygote $=$ heterozygote, $1=$ variant homozygote $)$, and additive $[(0,0)=$ wild-type homozygote, $(1,0)$ $=$ heterozygote,$(0,1)=$ variant homozygote] genetic models . Additive models included the additive 1 model (heterozygotes 
Table III. Characteristics of subjects with chronic kidney disease (CKD) and controls among individuals with type 2 diabetes mellitus.

\begin{tabular}{|c|c|c|c|}
\hline Characteristic & CKD & Controls & $\mathrm{P}$ \\
\hline No. of subjects & 636 & 1106 & \\
\hline Age (years) & $70.3 \pm 9.1$ & $65.7 \pm 9.8$ & $<0.0001$ \\
\hline Gender (male/female, \%) & $66.2 / 33.8$ & $66.6 / 33.4$ & 0.8711 \\
\hline $\operatorname{BMI}\left(\mathrm{kg} / \mathrm{m}^{2}\right)$ & $23.7 \pm 3.5$ & $23.9 \pm 3.5$ & 0.2782 \\
\hline Current or former smoker $(\%)$ & 19.6 & 27.3 & 0.0003 \\
\hline Hypertension (\%) & 81.3 & 72.1 & $<0.0001$ \\
\hline Systolic blood pressure (mmHg) & $152 \pm 29$ & $144 \pm 25$ & $<0.0001$ \\
\hline Diastolic blood pressure (mmHg) & $80 \pm 15$ & $79 \pm 15$ & 0.6703 \\
\hline Hypercholesterolemia (\%) & 31.5 & 31.6 & 0.9412 \\
\hline Serum total cholesterol (mmol/l) & $5.24 \pm 1.09$ & $5.18 \pm 1.03$ & 0.3655 \\
\hline Serum triglycerides $(\mathrm{mmol} / \mathrm{l})$ & $1.82 \pm 1.27$ & $1.66 \pm 1.09$ & 0.0154 \\
\hline Serum HDL-cholesterol (mmol/l) & $1.28 \pm 0.43$ & $1.30 \pm 0.36$ & 0.3991 \\
\hline Fasting plasma glucose (mmol/l) & $9.42 \pm 3.99$ & $9.41 \pm 3.89$ & 0.9718 \\
\hline Glycosylated hemoglobin (\%) & $7.15 \pm 1.94$ & $7.40 \pm 2.05$ & 0.1119 \\
\hline Serum creatinine $(\mathrm{mmol} / \mathrm{l})$ & $119.5 \pm 114.4$ & $62.4 \pm 13.0$ & $<0.0001$ \\
\hline eGFR $\left(\mathrm{ml} / \mathrm{min} / 1.73 \mathrm{~m}^{2}\right)$ & $46.5 \pm 11.8$ & $81.1 \pm 16.8$ & $<0.0001$ \\
\hline End stage renal failure (\%) & 3.3 & 0 & $<0.0001$ \\
\hline
\end{tabular}

Quantitative data are means \pm SD. Smoker, smoking of $\geq 10$ cigarettes daily; hypertension, systolic blood pressure of $\geq 140 \mathrm{mmHg}$ or diastolic blood pressure of $\geq 90 \mathrm{mmHg}$ (or both), or taking of antihypertensive medication; hypercholesterolemia, serum total cholesterol of $\geq 5.72 \mathrm{mmol} / \mathrm{l}$ or taking lipid-lowering medication.

versus wild-type homozygotes) and the additive 2 model (variant homozygotes versus wild-type homozygotes), which were analyzed simultaneously with a single statistical model.

We also performed a stepwise forward selection procedure to examine the effects of genotypes as well as of other covariates on CKD; each genotype was examined according to a dominant or recessive model on the basis of statistical significance in the multivariable logistic regression analysis. The P-levels for inclusion in and exclusion from the model were 0.25 and 0.1 , respectively. With the exception of the initial screen by the Chi-square test $(\mathrm{FDR}<0.05)$, a P-value of $<0.05$ was considered statistically significant. Statistical significance was examined by two-sided tests performed with JMP version 6.0 and JMP Genomics version 3.2 software (SAS Institute, Cary, NC).

\section{Results}

The characteristics of the 1742 study subjects are shown in Table III. Age, the prevalence of hypertension, systolic blood pressure, and the serum concentration of triglycerides were greater, whereas the percentage of smoker was lower, in subjects with CKD than in controls.

Comparisons of allele frequencies with the Chi-square test revealed that the 17 polymorphisms were related (allele frequency $\mathrm{P}<0.05$ ) to the prevalence of CKD (Table IV). Among these polymorphisms, the $8733 \mathrm{~T} \rightarrow \mathrm{C}$ polymorphism of ALOX5AP (rs3803278), the $\mathrm{C} \rightarrow \mathrm{T}$ (Ser532Leu) polymorphism of IRAK1 (rs1059703), the $2445 \mathrm{G} \rightarrow \mathrm{A}$ (Ala54Thr) polymorphism of $F A B P 2$ (rs1799883), and the $A \rightarrow G$
(Tyr243Cys) polymorphism of SERPINE1 (rs13306846) were significantly associated with the prevalence of CKD on the basis of an FDR for allele frequency of $<0.05$ (Table IV). The genotype distributions of the 17 polymorphisms in subjects with CKD and in controls are also shown in Table IV. The genotype distributions of four polymorphisms significantly (FDR <0.05) associated with CKD were in Hardy-Weinberg equilibrium both in CKD subjects and in controls except that for SERPINE1 in controls because of lack of variants in this group (Table V).

Multivariable logistic regression analysis with adjustment for age, sex, and the prevalence of smoking and hypertension revealed that the $8733 \mathrm{~T} \rightarrow \mathrm{C}$ polymorphism of $A L O X 5 \mathrm{AP}$ (dominant and additive 1 and 2 models), the $\mathrm{C} \rightarrow \mathrm{T}$ (Ser532Leu) polymorphism of IRAKI (dominant and additive 1 models), and the $2445 \mathrm{G} \rightarrow \mathrm{A}$ (Ala54Thr) polymorphism of FABP2 (dominant and additive 2 models) were significantly $(\mathrm{P}<0.05)$ associated with the prevalence of CKD in individuals with type 2 diabetes mellitus (Table VI). The variant $A$ allele of $F A B P 2$ was a risk factor for $\mathrm{CKD}$, whereas the variant $C$ allele of $A L O X 5 A P$ and $T$ allele of IRAK1 were protective against this condition.

Finally, we performed a stepwise forward selection procedure to examine the effects of genotypes for the four polymorphisms associated with CKD by the Chi-square test as well as of age, sex, and the prevalence of smoking and hypertension on CKD (Table VII). Age, hypertension, SERPINE1 genotype (dominat model), ALOX5AP genotype (dominat model), IRAK1 genotype (dominat model), and $F A B P 2$ genotype (dominat model), in descending order of 
Table IV. Genotype distributions of polymorphisms related (allele frequency $\mathrm{P}<0.05$ ) to chronic kidney disease $(\mathrm{CKD})$ among individuals with type 2 diabetes mellitus as determined by the Chi-square test.

\begin{tabular}{|c|c|c|c|c|c|c|}
\hline Gene symbol & Polymorphism & $\mathrm{dbSNP}^{\mathrm{a}}$ & CKD & Controls & $\mathrm{P}$ & FDR \\
\hline \multirow[t]{4}{*}{$A L O X 5 A P$} & $8733 \mathrm{~T} \rightarrow \mathrm{C}$ & rs 3803278 & & & 0.0051 & 0.0499 \\
\hline & TT & & $225(35.4)$ & $320(28.9)$ & & \\
\hline & $\mathrm{TC}$ & & $304(47.8)$ & $563(50.9)$ & & \\
\hline & $\mathrm{CC}$ & & $107(16.8)$ & $223(20.2)$ & & \\
\hline \multirow[t]{4}{*}{ IRAKI } & $\mathrm{C} \rightarrow \mathrm{T}($ Ser532Leu $)$ & rs1059703 & & & 0.0056 & 0.0499 \\
\hline & $\mathrm{CC}$ & & $459(72.2)$ & $735(66.5)$ & & \\
\hline & $\mathrm{CT}$ & & $71(11.2)$ & $155(14.0)$ & & \\
\hline & $\mathrm{TT}$ & & $106(16.7)$ & $215(19.5)$ & & \\
\hline \multirow[t]{4}{*}{$F A B P 2$} & 2445G $\rightarrow$ A $($ Ala54Thr $)$ & rs1799883 & & & 0.0069 & 0.0499 \\
\hline & GG & & $248(39.0)$ & 497 (44.9) & & \\
\hline & GA & & $291(45.8)$ & $475(43.0)$ & & \\
\hline & AA & & $97(15.3)$ & $134(12.1)$ & & \\
\hline \multirow[t]{3}{*}{ SERPINE1 } & $\mathrm{A} \rightarrow \mathrm{G}$ (Tyr243Cys) & rs13306846 & & & 0.0083 & 0.0499 \\
\hline & AA & & $632(99.4)$ & $1106(100)$ & & \\
\hline & $\mathrm{AG}$ & & $4(0.6)$ & $0(0)$ & & \\
\hline \multirow[t]{4}{*}{ IRAKI } & $\mathrm{A} \rightarrow \mathrm{C}$ & rs3027898 & & & 0.0137 & 0.0577 \\
\hline & AA & & $104(16.4)$ & 207 (18.7) & & \\
\hline & $\mathrm{AC}$ & & $70(11.0)$ & $152(13.8)$ & & \\
\hline & $\mathrm{CC}$ & & $461(72.6)$ & $746(67.5)$ & & \\
\hline \multirow[t]{4}{*}{$A P O E$} & $-219 \mathrm{G} \rightarrow \mathrm{T}$ & rs405509 & & & 0.0144 & 0.0577 \\
\hline & GG & & $42(6.6)$ & 107 (9.7) & & \\
\hline & GT & & $250(39.3)$ & $453(41.0)$ & & \\
\hline & TT & & $344(54.1)$ & $546(49.4)$ & & \\
\hline \multirow[t]{4}{*}{ IRAKI } & $\mathrm{C} \rightarrow \mathrm{T}$ & rs7061789 & & & 0.0196 & 0.0605 \\
\hline & $\mathrm{CC}$ & & $464(73.0)$ & $751(68.0)$ & & \\
\hline & $\mathrm{CT}$ & & $68(10.7)$ & $151(13.7)$ & & \\
\hline & $\mathrm{TT}$ & & $104(16.4)$ & $203(18.4)$ & & \\
\hline \multirow[t]{4}{*}{ SELE } & $561 \mathrm{~A} \rightarrow \mathrm{C}($ Ser128Arg $)$ & rs5361 & & & 0.0223 & 0.0605 \\
\hline & AA & & $582(91.5)$ & $1045(94.5)$ & & \\
\hline & $\mathrm{AC}$ & & $54(8.5)$ & $60(5.4)$ & & \\
\hline & $\mathrm{CC}$ & & $0(0)$ & $1(0.1)$ & & \\
\hline \multirow[t]{3}{*}{ СYР3А4 } & $13989 \mathrm{~A} \rightarrow \mathrm{G}(\mathrm{Ile} 118 \mathrm{Val})$ & NC_000007.12 & & & 0.0227 & 0.0605 \\
\hline & $\mathrm{AA}$ & & $636(100)$ & $1096(99.2)$ & & \\
\hline & $\mathrm{AG}$ & & $0(0)$ & $9(0.8)$ & & \\
\hline \multirow[t]{4}{*}{$S C A P$} & $2386 \mathrm{~A} \rightarrow \mathrm{G}(\mathrm{Ile} 796 \mathrm{Val})$ & rs 12487736 & & & 0.0270 & 0.0648 \\
\hline & AA & & $166(26.1)$ & $343(31.0)$ & & \\
\hline & AG & & $311(48.9)$ & $517(46.8)$ & & \\
\hline & GG & & $159(25.0)$ & $245(22.2)$ & & \\
\hline \multirow[t]{4}{*}{$A P O E$} & $3932 \mathrm{~T} \rightarrow \mathrm{C}(\mathrm{Cys} 112 \mathrm{Arg})$ & rs429358 & & & 0.0325 & 0.0696 \\
\hline & $\mathrm{TT}$ & & $503(79.1)$ & $916(82.8)$ & & \\
\hline & $\mathrm{TC}$ & & $125(19.7)$ & $184(16.6)$ & & \\
\hline & $\mathrm{CC}$ & & $8(1.3)$ & $6(0.5)$ & & \\
\hline \multirow[t]{4}{*}{ VKORC1 } & $2255 \mathrm{~T} \rightarrow \mathrm{C}$ & rs2359612 & & & 0.0356 & 0.0696 \\
\hline & $\mathrm{TT}$ & & $518(81.5)$ & $934(84.8)$ & & \\
\hline & $\mathrm{TC}$ & & $109(17.1)$ & $160(14.5)$ & & \\
\hline & $\mathrm{CC}$ & & $9(1.4)$ & $7(0.6)$ & & \\
\hline \multirow[t]{4}{*}{ IL10 } & $-592 \mathrm{~A} \rightarrow \mathrm{C}$ & rs1800872 & & & 0.0414 & 0.0696 \\
\hline & AA & & $304(47.8)$ & $470(42.5)$ & & \\
\hline & $\mathrm{AC}$ & & $266(41.8)$ & $505(45.7)$ & & \\
\hline & $\mathrm{CC}$ & & $66(10.4)$ & $131(11.8)$ & & \\
\hline
\end{tabular}


Table IV. Continued.

\begin{tabular}{|c|c|c|c|c|c|c|}
\hline Gene symbol & Polymorphism & $\mathrm{dbSNP}^{\mathrm{a}}$ & CKD & Controls & $\mathrm{P}$ & FDR \\
\hline \multirow[t]{4}{*}{$F 7$} & $11496 \mathrm{G} \rightarrow \mathrm{A}(\mathrm{Arg} 353 \mathrm{Gln})$ & rs6046 & & & 0.0434 & 0.0696 \\
\hline & $\mathrm{GG}$ & & $577(90.7)$ & $970(87.7)$ & & \\
\hline & GA & & $58(9.1)$ & $131(11.8)$ & & \\
\hline & AA & & $1(0.2)$ & $5(0.5)$ & & \\
\hline \multirow[t]{4}{*}{ IL10 } & $-819 \mathrm{~T} \rightarrow \mathrm{C}$ & rs1800871 & & & 0.0442 & 0.0696 \\
\hline & $\mathrm{TT}$ & & $304(47.8)$ & $471(42.6)$ & & \\
\hline & $\mathrm{TC}$ & & $266(41.8)$ & $504(45.6)$ & & \\
\hline & $\mathrm{CC}$ & & $66(10.4)$ & $131(11.8)$ & & \\
\hline \multirow[t]{4}{*}{ COL3Al } & $\mathrm{A} \rightarrow \mathrm{G}(\mathrm{Ile} 1205 \mathrm{Val})$ & rs2271683 & & & 0.0469 & 0.0696 \\
\hline & $\mathrm{AA}$ & & $525(82.6)$ & $872(78.8)$ & & \\
\hline & $\mathrm{AG}$ & & $105(16.5)$ & $217(19.6)$ & & \\
\hline & GG & & $6(0.9)$ & $17(1.5)$ & & \\
\hline \multirow[t]{4}{*}{ COMT } & $\mathrm{G} \rightarrow \mathrm{A}($ Val158Met $)$ & rs 4680 & & & 0.0498 & 0.0696 \\
\hline & $\mathrm{GG}$ & & $262(41.2)$ & $517(46.8)$ & & \\
\hline & GA & & $306(48.1)$ & $481(43.5)$ & & \\
\hline & AA & & $68(10.7)$ & $108(9.8)$ & & \\
\hline
\end{tabular}

Numbers in parentheses are percentages. ${ }^{\text {an }}$ instances where rs numbers in dbSNP were not detected, NCBI GenBank accession numbers are shown.

Table V. Hardy-Weinberg P-values in subjects with chronic kidney disease (CKD) and controls.

\begin{tabular}{lccc}
\hline Gene & Polymorphism & CKD & Controls \\
\hline ALOX5AP & 8733T $\rightarrow \mathrm{C}$ & 0.8020 & 0.3877 \\
IRAK1 & $\mathrm{C} \rightarrow \mathrm{T}($ Ser532Leu) & $0.2723^{\mathrm{a}}$ & $0.1738^{\mathrm{a}}$ \\
FABP2 & 2445G $\rightarrow \mathrm{A}$ (Ala54Thr) & 0.4457 & 0.2142 \\
SERPINE1 & $\mathrm{A} \rightarrow \mathrm{G}(\mathrm{T}$ yr243Cys) & 0.9366 & \\
\hline
\end{tabular}

${ }^{a}$ Genotype distributions in women.

statistical significance, were significant $(\mathrm{P}<0.05)$ and independent determinants of CKD in individuals with type 2 diabetes mellitus.

\section{Discussion}

We examined the possible relations of 24 polymorphisms in 22 candidate genes to the prevalence of CKD in 1742 Japanese individuals with type 2 diabetes mellitus. Our present study showed that the $8733 \mathrm{~T} \rightarrow \mathrm{C}$ polymorphism of $A L O X 5 A P$ (rs3803278), the $\mathrm{C} \rightarrow \mathrm{T}$ (Ser532Leu) polymorphism of IRAKI (rs1059703), and the $2445 \mathrm{G} \rightarrow \mathrm{A}$ (Ala54Thr) polymorphism of FABP2 (rs1799883) were significantly associated with CKD in such individuals.

Arachidonate 5-lipoxygenase-activating protein (ALOX5AP) is a regulator of a crucial pathway in the genesis of leukotriene inflammatory mediators (19), which are implicated in atherosclerosis both in a mouse model (20) and in human studies $(21,22)$. In a genome-wide study, the variants of ALOX5AP were associated with the prevalence of both myocardial infarction and stroke in Icelandic population by increasing leukotriene B4 production and inflammation in the arterial wall (23). In a case-control study, sequence variants in ALOX5AP were significantly associated with stroke in a central European population (24). Furthermore, the haplotypes constructed from the $162 \mathrm{~A} \rightarrow \mathrm{C}$ and $8733 \mathrm{~T} \rightarrow \mathrm{C}$ polymorphisms of ALOX5AP were significantly associated with a reduced risk for myocardial infarction in Japanese population (25). We have now shown that the $8733 \mathrm{~T} \rightarrow \mathrm{C}$ polymorphism of ALOX5AP was significantly associated with the prevalence of CKD in individuals with type 2 diabetes mellitus, with the $\mathrm{C}$ allele representing a protective factor for this condition. Effects of this polymorphism on the inflammatory processes of atherosclerosis may account for its association with CKD.

Interleukin 1 receptor-associated kinase 1 (IRAK1) is a key intracellular signaling protein that is activated by ligands of toll-like receptors. IRAK1 activation by interleukin 6 results in phosphorylation and activation of the transcription factor STAT3 and consequent transcriptional activation of the gene for C-reactive protein in Hep3B cells (26). cDNA microarray analysis revealed that IRAKI is expressed at high levels in human coronary arteries (27), and IRAK1 has been shown to be constitutively activated in blood mononuclear cells isolated from individuals with atherosclerosis (28). In addition, IRAK1 is implicated in regulation of expression of the gene for the anti-inflammatory cytokine interleukin 10 (28). These observations suggest that activation of the innate immune system in general, and of IRAK1 in particular, may contribute to the increased levels of inflammatory proteins associated 
Table VII. Effects of genotypes and other characteristics on chronic kidney disease among individuals with type 2 diabetes mellitus determined by a stepwise forward selection procedure $(\mathrm{P}<0.05)$.

\begin{tabular}{lcc}
\hline Variable & $\mathrm{P}$ & $\mathrm{R}^{2}$ \\
\hline Age & $<0.0001$ & 0.0419 \\
Hypertension & 0.0002 & 0.0060 \\
SERPINE1 $(A G+G G$ versus $A A)$ & 0.0017 & 0.0043 \\
ALOX5AP $(T C+C C$ versus $T T)$ & 0.0021 & 0.0042 \\
IRAK1 $(C T+T T$ versus $C C)$ & 0.0027 & 0.0039 \\
$F A B P 2(G A+A A$ versus $G G)$ & 0.0368 & 0.0019 \\
\hline
\end{tabular}

$\mathrm{R}^{2}$, contribution rate.

with atherosclerosis. Genetic variants of IRAKI were found to be associated with the plasma concentration of C-reactive protein in white women (29). Furthermore, we previously demonstrated that the $\mathrm{A} \rightarrow \mathrm{C}(\mathrm{rs} 3027898)$ and $\mathrm{C} \rightarrow \mathrm{T}$ (Ser532Leu, rs1059703) polymorphisms of IRAK1 were associated with atherothrombotic cerebral infarction in men (30). We have now shown that the $\mathrm{C} \rightarrow \mathrm{T}$ (Ser532Leu) polymorphism of IRAKI was significantly associated with the prevalence of CKD in individuals with type 2 diabetes mellitus, with the $T$ allele protecting against this condition. The $T$ allele of this polymorphism was previously shown to be protective against atherothrombotic cerebral infarction (30). This association may be attributable to effects of this polymorphism on vascular inflammation, although the underlying mechanism remains elucidated.

Fatty acid-binding protein 2 (FABP2) is an intracellular protein that is expressed only in the columnar absorptive epithelial cells of the small intestine. It contains a single ligand site that has a high affinity for saturated and unsaturated fatty acids, and it contributes to the absorption and intracellular transport of long-chain fatty acids (31). The product of $A$ allele of the $2445 \mathrm{G} \rightarrow \mathrm{A}$ (Ala54Thr) polymorphism of $F A B P 2$ possesses a greater affinity for long-chain fatty acids in vitro than does that of the $G$ allele (32). In addition, individuals with the $A$ allele of this polymorphism were found to be more insulin resistant than were those with the $G$ allele $(32,33)$. The $A$ allele was also shown to be associated with higher plasma levels of low density lipoprotein-cholesterol (34) or with dyslipidemia (high plasma concentration of triglycerides and low concentration of high density lipoprotein-cholesterol) (35). In addition, the $A$ allele of the $2445 \mathrm{G} \rightarrow \mathrm{A}$ (Ala54Thr) polymorphism was previously associated with atherothrombotic cerebral infarction in individuals with metabolic syndrome (36), and a parental history of stroke in the Swedish population (37). Moreover, it was associated with a 2- to 3.5fold increase in cardiovascular risk in dyslipidemic men with diabetes compared with their dyslipidemic nondiabetic counterparts; for nonfatal MI, stroke, or death from coronary heart disease, the corresponding hazard ratio was 3.0, whereas for stroke alone it was 3.5 (38). We have now shown that the 
$2445 \mathrm{G} \rightarrow \mathrm{A}$ (Ala54Thr) polymorphism was significantly associated with the prevalence of CKD in individuals with type 2 diabetes mellitus, with the $A$ allele representing a risk factor for this condition. The effects of this polymorphism on both insulin resistance and dyslipidemia may account for its association with the prevalence of CKD.

Our study has several limitations: i) We used an eGFR instead of a directly measured GFR to define CKD. ii) We were not able to obtain information about the underlying renal disease in each subject with CKD. Such information could be obtained by detailed clinical examination, including renal biopsy, but such diagnostic procedures are not considered feasible for a study whose subjects are recruited from the general population. iii) It is possible that one or more of the polymorphisms associated with CKD in the present study are in linkage disequilibrium with other polymorphisms in the same gene or in other nearby genes that are actually responsible for the development of this condition. iv) The functional relevance of the identified polymorphisms to gene transcription or to protein function was not determined in the present study.

In conclusion, our present results suggest that the $8733 \mathrm{~T} \rightarrow \mathrm{C}$ polymorphism of ALOX5AP, the $\mathrm{C} \rightarrow \mathrm{T}$ (Ser532Leu) polymorphism of $I R A K I$, and the $2445 \mathrm{G} \rightarrow \mathrm{A}$ (Ala54Thr) polymorphism of $F A B P 2$ are significantly associated with the prevalence of CKD in Japanese individuals with type 2 diabetes mellitus. Determination of genotypes for these polymorphisms may prove informative for assessment of the genetic risk for CKD in such individuals. Validation of our findings will require their replication with independent subject panels.

\section{Acknowledgements}

In addition to the authors, the following investigators participated in the study: H. Matsuo and T. Segawa (Gifu Prefectural General Medical Center); T. Hibino, K. Yajima, T. Fujimaki, and T. Kawamiya (Gifu Prefectural Tajimi Hospital); M. Oguri (Japanese Red Cross Nagoya First Hospital); A. Yasunaga, H. Park, N. Fuku, M.Tanaka, and H. Yoshida (Tokyo Metropolitan Institute of Gerontology). We also thank nursing and laboratory staff of the participating hospitals for their assistance.

\section{References}

1. Go AS, Chertow GM, Fan D, McCulloch CE and Hsu CY: Chronic kidney disease and the risks of death, cardiovascular events, and hospitalization. N Engl J Med 351: 1296-1305, 2004.

2. Weiner DE, Tighiouart H, Amin MG, et al: Chronic kidney disease as a risk factor for cardiovascular disease and all-cause mortality: a pooled analysis of community-based studies. J Am Soc Nephrol 15: 1307-1315, 2004

3. Ninomiya T, Kiyohara Y, Kubo M, et al: Chronic kidney disease and cardiovascular disease in a general Japanese population: the Hisayama Study. Kidney Int 68: 228-236, 2005.

4. Anavekar NS, McMurray JJ, Velazquez EJ, et al: Relation between renal dysfunction and cardiovascular outcomes after myocardial infarction. N Engl J Med 351: 1285-1295, 2004.

5. Weiner DE, Tighiouart H, Stark PC, et al: Kidney disease as a risk factor for recurrent cardiovascular disease and mortality. Am J Kidney Dis 44: 198-206, 2004.

6. Tozawa M, Iseki K, Iseki C, Oshiro S, Ikemiya $\mathrm{Y}$ and Takishita S: Influence of smoking and obesity on the development of proteinuria. Kidney Int 62: 956-962, 2002.
7. de Jong PE and Brenner BM: From secondary to primary prevention of progressive renal disease: the case for screening for albuminuria. Kidney Int 66: 2109-2118, 2004.

8. Iseki K, Oshiro S, Tozawa M, Ikemiya Y, Fukiyama K and Takishita S: Prevalence and correlates of diabetes mellitus in a screened cohort in Okinawa, Japan. Hypertens Res 25: 185-190, 2002.

9. Muntner P, Coresh J, Smith JC, Eckfeldt J and Klag MJ: Plasma lipids and risk of developing renal dysfunction: the atherosclerosis risk in communities study. Kidney Int 58: 293-301, 2000.

10. Kovesdy CP, Sharma K and Kalantar-Zadeh K: Glycemic control in diabetic CKD patients: where do we stand? Am J Kidney Dis 52: 766-777, 2008

11. Kikkawa R, Togawa M, Isono M, Isshiki K and Haneda M: Mechanism of the progression of diabetic nephropathy to renal failure. Kidney Int 62 (Suppl): S39-S40, 1997.

12. Valmadrid CT, Klein R, Moss SE and Klein BE: The risk of cardiovascular disease mortality associated with microalbuminuria and gross proteinuria in persons with older-onset diabetes mellitus. Arch Intern Med 160: 1093-1100, 2000.

13. Imai E, Matsuo S, Makino H, et al: Chronic Kidney Disease Japan Cohort (CKD-JAC) study: design and methods. Hypertens Res 31: 1101-1107, 2008.

14. National Kidney Foundation: K/DOQI clinical practice guidelines for chronic kidney disease: evaluation, classification, and stratification. Am J Kidney Dis 39 (2 Suppl 1): S1-S266, 2002.

15. The Expert Committee on the Diagnosis and Classification of Diabetes Mellitus: Report of the Expert Committee on the Diagnosis and Classification of Diabetes Mellitus. Diabetes Care 21: S5-S19, 1998.

16. Kuzuya T, Nakagawa S, Satoh J, et al: Report of the Committee on the Classification and Diagnosis Criteria of Diabetes Mellitus. Diabetes Res Clin Pract 55: 65-85, 2002.

17. Itoh Y, Mizuki N, Shimada T, et al: High-throughput DNA typing of HLA-A, -B, -C, and -DRB1 loci by a PCR-SSOPLuminex method in the Japanese population. Immunogenetics 57: 717-729, 2005

18. Benjamini Y and Hochberg Y: Controlling the false discovery rate: a practical and powerful approach to multiple testing. J Royal Stat Soc Ser B 57: 289-300, 1995.

19. Dixon RA, Diehl RE, Opas E, et al: Requirement of a 5lipoxygenase-activating protein for leukotriene synthesis. Nature 343: 282-284, 1990

20. Mehrabian M, Allayee H, Wong J, et al: Identification of 5lipoxygenase as a major gene contributing to atherosclerosis susceptibility in mice. Circ Res 91: 120-126, 2002.

21. Brezinski DA, Nesto RW and Serhan CN: Angioplasty triggers intracoronary leukotrienes and lipoxin A4. Impact of aspirin therapy. Circulation 86: 56-63, 1992.

22. Spanbroek R, Grabner R, Lotzer K, et al: Expanding expression of the 5-lipoxygenase pathway within the arterial wall during human atherogenesis. Proc Natl Acad Sci USA 100: 1238-1243, 2003.

23. Helgadottir A, Manolescu A, Thorleifsson G, et al: The gene encoding 5-lipoxygenase activating protein confers risk of myocardial infarction and stroke. Nat Genet 36: 233-239, 2004.

24. Lõhmussaar E, Gschwendtner A, Mueller JC, et al: ALOX5AP gene and the PDE4D gene in a central European population of stroke patients. Stroke 36: 731-736, 2005.

25. Kajimoto K, Shioji K, Ishida C, et al: Validation of the association between the gene encoding 5-lipoxygenase-activating protein and myocardial infarction in a Japanese population. Circ J 69: 1029-1034, 2005.

26. Zhang D, Sun M, Samols D and Kushner I: STAT3 participates in transcriptional activation of the C-reactive protein gene by interleukin-6. J Biol Chem 271: 9503-9509, 1996.

27. Satterthwaite G, Francis SE, Suvarna K, et al: Differential gene expression in coronary arteries from patients presenting with ischemic heart disease: further evidence for the inflammatory basis of atherosclerosis. Am Heart J 150: 488-499, 2005.

28. Huang Y, Li T, Sane DC and Li L: IRAK1 serves as a novel regulator essential for lipopolysaccharide-induced interleukin-10 gene expression. J Biol Chem 279: 51697-51703, 2004.

29. Lakoski SG, Li L, Langefeld CD, et al: The association between innate immunity gene (IRAK1) and C-reactive protein in the Diabetes Heart Study. Exp Mol Pathol 82: 280$283,2007$. 
30. Yamada Y, Metoki N, Yoshida H, et al: Genetic factors for ischemic and hemorrhagic stroke in Japanese individuals. Stroke 39: 2211-2218, 2008.

31. Lowe JB, Sacchettini JC, Laposata M, McQuillan JJ and Gordon JI: Expression of rat intestinal fatty acid-binding protein in Escherichia coli. Purification and comparison of ligand binding characteristics with that of Escherichia coli-derived rat liver fatty acid-binding protein. J Biol Chem 262: 5931-5937, 1987.

32. Baier LJ, Sacchettini JC, Knowler WC, et al: An amino acid substitution in the human intestinal fatty acid binding protein is associated with increased fatty acid binding, increased fat oxidation, and insulin resistance. J Clin Invest 95: 1281-1287, 1995.

33. Yamada K, Yuan X, Ishiyama S, et al: Association between Ala54Thr substitution of the fatty acid-binding protein 2 gene with insulin resistance and intra-abdominal fat thickness in Japanese men. Diabetologia 40: 706-710, 1997.

34. Galluzzi JR, Cupples LA, Otvos JD, Wilson PW, Schaefer EJ and Ordovas JM: Association of the A/T54 polymorphism in the intestinal fatty acid binding protein with variations in plasma lipids in the Framingham Offspring Study. Atherosclerosis 159: 417-424, 2001
35. Guettier JM, Georgopoulos A, Tsai MY, et al: Polymorphisms in the fatty acid-binding protein 2 and apolipoprotein C-III genes are associated with the metabolic syndrome and dyslipidemia in a South Indian population. J Clin Endocrinol Metab 90: 1705-1711, 2005.

36. Yamada Y, Kato K, Oguri M, et al: Association of genetic variants with atherothrombotic cerebral infarction in Japanese individuals with metabolic syndrome. Int J Mol Med 21: 801-808, 2008.

37. Carlsson M, Orho-Melander M, Hedenbro J, Almgren P and Groop LC: The T 54 allele of the intestinal fatty acid-binding protein 2 is associated with a parental history of stroke. J Clin Endocrinol Metab 85: 2801-2804, 2000.

38. Georgopoulos A, Bloomfield H, Collins D, et al: Codon 54 polymorphism of the fatty acid binding protein (FABP) 2 gene is associated with increased cardiovascular risk in the dyslipidemic diabetic participants of the Veterans Affairs HDL intervention trial (VA-HIT). Atherosclerosis 194: 169-174, 2007. 